\title{
Gıda Endüstrisinde Elektrolize Su Kullanımı
}

\author{
Asli $\mathrm{Aksoy}^{1^{*}}$ \\ ${ }^{1}$ Haliç Üniversitesi, Güzel Sanatlar Fakültesi, Gastronomi ve Mutfak Sanatları Bölümü, İstanbul, Türkiye (ORCID: 0000-0002-7775-6514)
}

(İlk Geliş Tarihi 22 Nisan 2020 ve Kabul Tarihi 23 Mayıs 2020)

(DOI: 10.31590/ejosat.725282)

ATIF/REFERENCE: Aksoy, A. (2020). Gıda Endüstrisinde Elektrolize Su Kullanımı. Avrupa Bilim ve Teknoloji Dergisi, (19), 254262.

\section{$\ddot{O ̈ z}$}

Gıda, insan yaşamının sürdürülebilmesi için elzem unsurlardan biridir. İnsan sağlığının korunması için mutlaka gıda güvenliğinin sağlanması gerekir. Gida güvenliğinin sağlanmasında 1sıl olan ve olmayan birçok yöntem mevcuttur. Isıl olmayan yöntemler arasında geleneksel kimyasal çözeltiler kullanılarak yapılan dezenfeksiyon uygulamaları oldukça önemli bir yere sahiptir. Geçmişten günümüze kadar gıda endüstrisinde dezenfektan olarak kullanılan birçok kimyasal madde mevcuttur. Kullanılan kimyasal maddenin türüne göre gıdanın yapısının deformasyona uğraması, gıdaya temas eden yüzeylerde korozyon ve dezenfeksiyon sonrası kimyasal kalıntı varlığı gibi çeşitli olumsuz faktörler söz konusu olduğundan, geleneksel dezenfektanlara alternatifler araştırılmaya başlanmıştır. Bu bağlamda elektrolize suyun dezenfektan olarak kullanımı birçok ülkede yaygınlaşmaktadır. Toksik olmaması, kullanım kolaylığı, ekonomik, güvenli ve çevre dostu olması nedeni ile elektrolize su üzerinde son yıllarda oldukça fazla çalışma yapılmaktadır. Bu derlemede elektrolize su, elektrolize su çeşitleri ve etki mekanizmaları, gıda endüstrisindeki kullanım alanları ve uygulamaları hakkında bilgi verilmiştir.

Anahtar Kelimeler: Elektrolize su, Asidik elektrolize su, Alkali elektrolize su, Dekontaminasyon, Dezenfeksiyon.

\section{Use of Electrolyzed Water in Food Industry}

\begin{abstract}
Food is one of the essential factors in sustaining human life. Food safety must be ensured to protect human health. Both thermal and non-thermal methods are available means of ensuring food safety. In the non-thermal methods disinfection applications using traditional chemical solutions have an important place. There are many chemicals having been used in the food industry as disinfectant from the past to the present. Since various negative factors associated with the type of the chemicals used such as deformation of the food structure, corrosion on food contact surfaces and the presence of chemical residues after disinfection, alternatives to traditional disinfectants have been investigated. In this context, the use of electrolyzed water as a disinfectant is getting common in many countries. A lot of research has been conducted on electrolyzed water in recent years since it is not only non-toxic, easy to use and cheap but also safe and environmentally friendly. This review contains information about electrolyzed water, types of electrolyzed water and their mechanism of action as well as areas of use and application in the food industry.
\end{abstract}

Keywords: Electrolyzed water, Acidic electrolyzed water, Alkaline electrolyzed water, Decontamination, Disinfection.

\footnotetext{
* Sorumlu Yazar: Haliç Üniversitesi, Güzel Sanatlar Fakültesi, Gastronomi ve Mutfak Sanatları Bölümü, İstanbul, Türkiye, ORCID: 0000-00027775-6514, aksoyas@gmail.com
} 


\section{Giriş}

Minimal işlem görmüş gıdalar mikrobiyal kaynaklı hastalık ve salgınlara neden olabilmektedirler. Örneğin EFSA ("European Food Safety Authority") verilerine göre beş Avrupa ülkesi, tüketime hazır gıda kaynaklı Salmonella agona nedeniyle 2017'nin başlarından 2018 Temmuz ayına kadar 147 kişinin, 2014-2016 yılları arasında ise 25 kişinin hastalandığını duyurmuştur (İngiltere'de 129 kişi, Finlandiya'da 15 kişi, Danimarka, Almanya ve İrlanda'da birer kişi) (Anon., 2018a).

Ayrıca yine EFSA tarafından 2018 yılı Temmuz ayı içerisinde dondurulmuş sebze kaynaklı Listeria monocytogenes salgını açıklanmıştır (Anon., 2018b). Bu patojen bakterilerin yanısıra hepatit, norwalk ve rota gibi virüsler, Cyclospora ve Cryptosporidium gibi parazitler, Penicillium ve Aspergillus türü küfler gibi gıdalarda sıklıkla rastlanan diğer patojen mikroorganizmalar insanlarda çeşitli hastalıklara neden olmaktadırlar (Appleton, 2000; Anon., 2018c).

Bu hastalıkların nedeni, gıdaların üretilmesi ya da işlenmesi sırasında mikrobiyal kontaminasyona maruz kalabilmesidir. Özellikle kullanıma ya da tüketime hazır meyve ve sebzelerde bu durum daha da önem kazanmaktadır. Ayrıca çiğ tavuk eti gibi bazı gıdalar, doğal mikrofloraları sebebiyle gıda güvenliği açısından bazı riskler taşımaktadırlar. Bu nedenle bir gıda tesisinde gıda ve gıda ile temas eden yüzeylerin (ekipman vb.) uygun bir yöntemle dezenfeksiyonu sağlanmalı, İyi Hijyen Uygulamaları ("Good Hygiene Practises", GHP) gerçekleştirilmelidir (Aksoy, 2003).

Isıl işlemlerin neden olduğu kalite kayıpları ve enerji sarfiyatı gibi nedenlerden dolayı geleneksel dezenfeksiyon prosedürlerine alternatif olarak yeni metotlar araştırılmaya başlanmıştır. Elektrolize su ("electrolyzed water") uygulaması, bu modern yöntemlerden biridir ve elektrolize su birçok ülkede dezenfektan olarak kullanılmaktadır (Anon., 2012; Hricova ve ark., 2008; Poçan, 2012; Yudin ve ark., 2011). Toksik olmaması, çevreye zarar vermemesi, pahalı olmaması, temizleme süresinin kısa ve kullanımının kolay olması gibi nedenlerle, elektrolize su üzerinde son yıllarda oldukça fazla çalışma yapılmaktadır (Poçan, 2012; Turantaş ve ark., 2018). Bu çalışmada elektrolize suyun gıda endüstrisinde kullanımı incelenmiş̧; uygulamalar ile ilgili bilgiler verilmiştir.

\section{Elektrolize Su}

Anot ve katodun bir membran yardımıyla ayrıldığı düzenekte, seyreltik sodyum klorür $(\mathrm{NaCl})$ çözeltisinin elektrolizi ile elde edilen ürün "elektrolize su" olarak isimlendirilmektedir (Kim ve ark.,2001; Koseki ve ark.,2001; Al-Haq ve ark., 2002; Sharma ve Demirci, 2002; Kiura ve ark., 2002; Len ve ark., 2002; Buck ve ark., 2003; Hati ve ark., 2012).

Saf su iletkenlik açısından güçlü değildir ve elektriği iletecek düzeyde iyon içermediğinden $\left(25^{\circ} \mathrm{C}^{\prime}\right.$ de $1 \times 10^{-7} \mathrm{M}$ Hidrojen $\left(\mathrm{H}^{+}\right)$ iyonu ve $1 \times 10^{-7} \mathrm{M}$ Hidroksil $\left(\mathrm{OH}^{-}\right)$iyonu), elektrolizin gerçekleşmesi için genelde iletkenliği arttırıcı olarak suya dezenfeksiyon etkisi de olan $\mathrm{NaCl}$ eklenmektedir (Millioğlu, 2006; Poçan 2012). Elektrolit olarak tuzlu su içeren elektroliz hücresindeki elektrotlardan doğru akım geçirildiğinde, pozitif elektrottan negatif elektroda doğru bir akım gerçekleşir. Dolayısıyla anot pozitif yüklenirken, katot negatif yüke sahip olur. Bu durumda elektrotlar arasında meydana gelen elektrik alan nedeniyle pozitif iyonlar katoda göçerken, negatif iyonlar anoda doğru hareket eder (Poçan, 2012).

$\mathrm{Bu}$ şekilde gerçekleşen oksidoredüksiyon (redoks) reaksiyonlarında elektron alan (oksidan) ve elektron veren (redüktan) moleküller, "redoks çifti" olarak değerlendirilmektedir. Bir redoks çiftinin elektron kaybetme olayı ise "Oksidasyon Redüksiyon Potansiyeli (ORP)" olarak tanımlanmaktadır (Poçan 2012). ORP değeri, elektroliz sonucu ortaya çıkan serbest klor konsantrasyonu ile birlikte elektrolize suyun etkinliğini belirleyen faktörlerden biridir (Aksoy, 2003).

Bunun dışında serbest klor konsantrasyonu, $\mathrm{pH}$, sıcaklık, elektrolitin ve suyun akış hızı, tuz konsantrasyonu, elektrolizin gerçekleşme süresi, kullanılan elektrolitin tipi, suyun sertliği, muhafaza koşulları, üründeki organik madde varlığı ve kirlilikler, ürüne uygulama şekli (daldırma, spreyleme vb.) elektrolize suyun dezenfektan özelliğini etkilemektedir (Millioğlu, 2006, Poçan, 2012; Rahman ve ark., 2016; Athayde ve ark., 2018).

\subsection{Elektrolize Su Çeşitleri ve İnaktivasyon Mekanizması}

$\mathrm{Su}$, yapısında bulunan $\mathrm{H}^{+}$veya $\mathrm{OH}^{-}$iyonlarının konsantrasyonuna bağlı olarak, asidik ya da alkali özellik gösterir. Eğer suyun $\mathrm{H}^{+}$ iyonları miktarı fazla ise asidik; $\mathrm{OH}^{-}$iyonları miktarı fazla ise alkali özellik göstermektedir. $\mathrm{H}^{+}$ve $\mathrm{OH}^{-}$iyonları miktarlarının eşit olduğu durumda ise su nötrdür (Millioğlu, 2006).

Suyun elektrolizi sonucu anotta "asidik su", katotta ise "alkali su" oluşmaktadır (Poçan, 2012). Asidik elektrolize su (ASES) "elektrolize yükseltgen su" (Özer ve K1lı̧, 2012), "süperoksitlenmiş su" (Külekçi, 2005), "elektrolize okside su" (Huang ve ark., 2008) olarak da adlandırılabilmektedir. Alkali elektrolize su (ALES) ise "bazik elektrolize su" (Hricova ve ark., 2008) ya da "elektrolize indirgen su" (Hao ve ark., 2011) olarak isimlendirilebilmektedir.

ASES'yun pH'1 2-3 arasında; ORP'i 1100 mV'dan fazla ve serbest klor konsantrasyonu (SKK) ise 10-90 ppm arasinda iken; ALES'yun pH'1 10-13 ve ORP'i (-800)-(-900) mV arasında değişmektedir (Hricova ve ark., 2008).

"Nötral elektrolize su (NES)" ise pH'ı 7 olan, asidik ve alkali suyun avantajlarını kombine olarak barındıran elektrolize su çeşididir. Hücre membranına kolayca nüfuz edebildiği gibi, ekipman ve cilt için daha az korozif etkiye sahiptir. Nötral pH'ta serbest klor kaybı daha az olduğu için raf ömrü daha uzundur. NES, sahip olduğu yüksek ORP ve serbest klor içeriği ile serbest hidroksil grupları nedeniyle antimikrobiyal etkiye sahiptir (Monnin ve ark., 2012). 
ASES, gıda kaynaklı hastalıkların önlenmesi amacıyla ilk kez Japonya'da geliştirilmiş ve kullanılmaya başlanmıştır (Millioğlu, 2006). Güçlü oksidasyon potansiyeline sahiptir olan ASES dezenfeksiyon amaçlı kullanılmaktadır (Yoshida ve ark., 2004). Ayrıca hastane enfeksiyonlarının kontrolü için de değerlendirilebilmektedir (Günaydın ve ark., 2012).

ALES ise güçlü redüksiyon potansiyeline sahiptir ve gıdaları temizleme amaçlı tercih edilmektedir (Hsu, 2005). Aynı zamanda kesme tahtası gibi mutfak malzemelerinin ve endüstriyel süt sağım makinası gibi ekipmanların yüzeyinden yağ ve kiri uzaklaştırmak amacıyla kullanılabilmektedir (Anonim, 2011). Yapılan bir çalışmada kalitesi düşük pirinçler ve ALES kullanılarak pişirilen pilavın, şebeke suyu ile pişirilen pilava göre daha iyi pişmiş ve yumuşak taneli olduğu, ayrıca daha geç bozulduğu tespit edilmiştir (Onishi ve ark., 2001).

Elektrolize suyun inaktivasyon mekanizmasıyla ilgili çeşitli çalışmalar yapılmıştır. ASES'da yüksek ORP değerlerinde ve SKK'da inaktivasyon özelliği artmaktadır (Koseki ve ark., 2001). Aynı zamanda ASES'yun pH'ının düşük olması da inaktivasyon üzerinde olumlu bir etkendir (Özer ve Kılıç, 2012).

Klorun inaktivasyon etkisi, mikroorganizmalardaki enzimlerin sülfidril (SH) gruplarının geri dönüşümsüz oksidasyonuna neden olmasından kaynaklanmaktadır (Külekçi, 2005). Bir serbest klor türü olan hipokloröz asit (HOCl) ise, hidroksil serbest radikali oluşturmakta, meydana gelen bu radikal de yükseltgenerek mikroorganizmaların inhibisyonuna neden olmaktadır (Koseki ve ark., 2001, Aksoy, 2003). Hipokloritler $\left(\mathrm{OCl}^{-}\right)$ise sitoplazmik bileşiklerle toksik özellikte N-kloro bileşikleri oluşturma suretiyle mikroorganizma hasarına yol açmaktadır (Külekçi, 2005).

Klorun etkinliği, pH düştükçe yani asitlik arttıkça artmaktadır. Dolayısıyla asitlik için ortamdaki hipoklorit iyonu miktarından çok, hipokloröz iyonu miktarı önemlidir. Ayrıca klor bileşiklerinin etkinliği konsantrasyon ve sıcaklıkla doğru orantılıdır. Yapılan bir çalışmada klor konsantrasyonundaki iki kat artışın dezenfeksiyon süresini $\% 30$ oranında azalttığı; sıcaklıktaki $10^{\circ} \mathrm{C}^{\prime}$ lik artışın ise bu süreyi \%50-\%65 oranında kısalttığı gösterilmiştir (Külekçi, 2005).

ASES'yun stabilitesi ile ilgili yapılan bir çalışmada; ASES'yun karanlık şartlarda 1 yıl süreyle özelliklerini koruyabildiği, güneş ışığına üç gün maruz bırakıldığında ise 1 yıl boyunca pH'ını muhafaza edebildiği açığa çıkartılmıştır. Aynı çalışmada uygun muhafaza koşulları (karanlık ve kapalı ortam) sağlanmadığında ise, ALES'yun özelliklerinin değişebildiği saptanmıştır (Koseki ve Itoh, 2000).

\subsection{Gıda Endüstrisinde Elektrolize Su Uygulamaları, Avantajları ve Dezavantajları}

ALES'yun gıda endüstrisinde yemeklerin pişirme süresinin kısaltılması, pirinç pilavının daha lezzetli olması, çay ve kahve gibi içeceklerde hızlıca renk oluşumunun sağlanması, alkolün metabolizmadan daha kısa zamanda uzaklaştırılması, gıdaların sindirilebilirliğinin artırılması, balık vb. gibi yoğun kokuya sahip gıdaların kokularının giderilmesi, sert sebze ve etlerin pişirilmesi, evcil hayvanların parazitlerden arındırılması gibi nedenlerle kullanıldığı bilinmektedir (Millioğlu, 2006; Poçan ve ark., 2011). Yapılan bir çalışmada da, et emülsiyonlarının hazırlanmasında pH'1 7,4 olan musluk suyu yerine; pH'1 10 olan elektrolize suyun kullanılmasının daha kaliteli bir emülsiyon oluşturduğu, emülsiyon kapasitesini arttırdığı belirtilmiştir (Poçan, 2012).

Gerçekleştirilen bazı çalışmalar sonucunda ASES'yun antimikrobiyal ve antiviral etkisi açığa çıkartılmıştır. ASES genellikle isıya hassas gıdaların sterilizasyonu için tercih edilmektedir. Mikroorganizma süspansiyonlarının inaktivasyonunda da başarılı sonuçlar veren ASES'yun kullanım alanları kısaca şu şekilde özetlenebilir: yüzey (kesme tahtaları, proses eldivenleri, biofilmler, makine ve ekipman yüzeyleri (süt sağım makineleri vb), zemin ve duvar yüzeyleri), mezbaha ortamları, proses suları (ayrıca buz) ve gıdaların (sebze ve meyveler, balık ve su ürünleri, yumurta, karkas (sığır, domuz, tavuk)) dezenfeksiyonu, pestisitlerin uzaklaştırılması. Aynı zamanda diş hekimliği ve bazı tıp uygulamalarında da tercih edilmektedir (Jung ve ark., 1996; Koseki ve ark., 2001; Park ve ark., 2002a; Park ve ark., 2002b; Aksoy, 2003; Buck ve ark., 2003; Hricova,2008, Özer ve Kılıç, 2012).

Elektrolize su birçok avantaj sağlamaktadır. Elde edilirken kimyasal olarak yalnızca $\mathrm{NaCl}$ çözeltisi kullanıldığı ve toksik olmadığı için çevreye zarar vermemektedir. Ortam pH'ının düşük olduğu değerlerde dezenfeksiyon sağlayabilme özelliğinde olan $\mathrm{HOCl}$, zayıf bir asit olduğundan, daha az aktif olan $\mathrm{OCl}^{-}{ }^{-}$e kolayca hidroliz olmaz (Koseki ve ark.,2001; Koseki ve ark., 2002; Aksoy, 2003). Bunun yanında güçlü asidik özellikte olan elektrolize okside su (GASES); hidroklorik asit veya sülfürik asit gibi korozif değildir (Huang ve ark., 2008). Elektrolize su jeneratörü temin edildikten sonra; işletme açısından maliyete neden olan unsurlar sadece su, tuz ve elektrik enerjisidir (Anonim, 2011). Dolayısıyla temizlik ve dezenfeksiyonda kullanılan diğer kimyasallara kıyasla, daha ekonomiktir ve uygulaması kolaydır (Poçan, 2012). Elektrolize su uygulamasında 1sıl işlemlerin neden olduğu kayıplar, uygulama sonrası yüzeylerde klor kalıntısı, ayrıca tehlikeli kimyasalların depolanması ve taşınması sırasında oluşabilecek riskler de söz konusu değildir (Özer ve Kılıç, 2012).

Elektrolize suyun bazı dezavantajları da mevcuttur. Elektrolize suya, elektroliz vasıtasıla sürekli $\mathrm{HOCl}, \mathrm{H}^{+}$ve $\mathrm{Cl}_{2}$ takviyesi yapılmazsa, çözelti hızlıca antimikrobiyal özelliğini kaybetmektedir. Ayrıca güçlü asidik özellikte olduğu ve serbest klor içerdiği için sentetik reçinenin bozulması ve metal korozyonu gibi problemlere yol açabileceği belirtilmektedir (Anonim, 2011).

\subsection{Elektrolize Su ile Yapılan Çalışmalara Örnekler}

Günümüzde elektrolize su, başta sebze-meyve ve hayvansal ürünler olmak üzere birçok gıda ve gıdalarla temas eden yüzeylerde mikrobiyal inaktivasyonun sağlanması, gıdalardan pestisitlerin ve mikotoksinlerin uzaklaştırılması gibi çeşitli amaçlarla kullanılmaktadır.

Sebze ve meyvelerin dokusal ve duyusal kalitesini bozmadan, ayrıca isıl işleme gerek kalmadan gerçekleştirilen elektrolize su uygulamaları oldukça çeşitlidir. Tablo 1'de bu çalışmalara bazı örnekler verilmiştir. 
Tablo 1. Sebze ve Meyvelerde Elektrolize Su ile Yapılan Bazı Çalışmalar

\begin{tabular}{|c|c|c|c|c|}
\hline Ürün & $\begin{array}{l}\text { İncelenen } \\
\text { parametre }\end{array}$ & Uygulama & Sonuç & Kaynak \\
\hline Marul & $\begin{array}{l}\text { Mezofilik aerobik } \\
\text { bakteri (MAB) ve } \\
\text { koliform bakteri }\end{array}$ & $\begin{array}{l}10 \text { dk.,20 ppm'lik ASES (pH:2.7, } \\
\text { ORP: } 1099 \mathrm{mV}), 30 \mathrm{ppm} \text { 'lik ASES } \\
\text { (pH:2.7, ORP: } 1100 \mathrm{mV} \text { ) ile } 200 \\
\text { ppm'lik NaOCl ile muamele }\end{array}$ & $\begin{array}{l}\text { MAB ve koliform bakteri sayılarındaki } \\
\text { azalma sırasıyla şöyledir: } \\
30 \text { ppm'lik ASES ile: } 1.30 \log \text { ve } 1.59 \mathrm{log} \\
200 \text { ppm'lik NaOCl ile: } 1.22 \log \text { ve } 1.42 \mathrm{log} \\
20 \text { ppm'lik ASES ile: } 1.21 \log \text { ve } 1.29 \log \end{array}$ & $\begin{array}{l}\text { Aksoy, } \\
2003 .\end{array}$ \\
\hline $\begin{array}{l}\text { Elma, } \\
\text { armut, } \\
\text { portakal }\end{array}$ & $\begin{array}{l}\text { Listeria innocua ve } \\
\text { Escherichia coli } \\
\text { O157:H7 }\end{array}$ & $\begin{array}{l}\text { SKK: } 100 \text { ve } 200 \text { ppm olan ASES } \\
\text { (pH: } 2.68-2.93 \text {, ORP: } 1079-1111 \\
\text { mV), NES (pH: } 8.18-8.33 \text {, ORP: } \\
\text { 725-736 mV) ve NaOCl (pH: 8-8.5, } \\
\text { ORP: } 731-759 \mathrm{mV} \text { ) ile muamale }\end{array}$ & $\begin{array}{l}\text { En yüksek inaktivasyonun } 200 \text { ppm'lik } \\
\text { ASES ile sağlandığı, } 100 \text { ppm'lik ASES ve } \\
\text { NES uygulama sonuçlarının benzer olduğu } \\
\text { belirlenmiştir. }\end{array}$ & $\begin{array}{l}\text { Graca ve } \\
\text { ark., } \\
2010 .\end{array}$ \\
\hline Ispanak & $\begin{array}{l}\text { Pestisit (acephate, } \\
\text { omethoate ve } \\
\text { DDVP) }\end{array}$ & $\begin{array}{l}30 \mathrm{dk} . \text { ASES (pH: } 2.3, \text { SKK: } 70 \\
\text { ppm, ORP: } 1170 \mathrm{mV} \text { ) ve ALES } \\
\text { (pH 11.6, ORP: }-860 \mathrm{mV} \text { ) ile } \\
\text { muamele }\end{array}$ & $\begin{array}{l}\text { Pestisit kalıntısında ASES ile \%59-74, } \\
\text { ALES ile ise \% } 46-86 \text { azalma saptanmış, } \\
\text { ayrıca C vitamini miktarı değişmemiştir. }\end{array}$ & $\begin{array}{l}\text { Hao ve } \\
\text { ark., } \\
2012 .\end{array}$ \\
\hline Kiraz & $\begin{array}{l}\text { Kalite özellikleri, } \\
\text { küf ve raf ömrü }\end{array}$ & $\begin{array}{l}3 \text { dk. süreyle } 25,50,100,200,300 \\
\text { ve } 400 \text { ppm serbest klor içeriğine } \\
\text { sahip elektrolize su ile muamele ve } \\
\text { sonrasında } 30 \text { gün depolama }\end{array}$ & $\begin{array}{l}\text { Gaz kompozisyonundaki değişim, ağırlık } \\
\text { kaybı, brix, pH, sertlik, su aktivitesi, renk, } \\
\text { antosiyanin profili, duyusal özellikler ve küf } \\
\text { analizlerine bağlı olarak, SKK'u } 100 \\
\text { ppm'den düşük ASES'yun raf ömrünü } \\
\text { arttırmada etkili olduğu belirlenmiştir. }\end{array}$ & $\begin{array}{l}\text { Hayta, } \\
2014 .\end{array}$ \\
\hline $\begin{array}{l}\text { Havuç } \\
\text { 1spana, } \\
\text { biber, } \\
\text { turp, } \\
\text { patates, } \\
\text { salatalik }\end{array}$ & $\begin{array}{l}\text { MAB ve görünüm } \\
\text { (renk) }\end{array}$ & $\begin{array}{l}4 \mathrm{dk} \text {. ASES uygulamas1 (pH: } 6.8, \\
\text { SKK: } 15,20,30 \text { ve } 50 \mathrm{ppm})\end{array}$ & $\begin{array}{l}\text { 0.6-2.6 log azalma saptanmıştır. } \\
\text { En güçlü etki } 50 \text { ppm'lik ASES ile } \\
\text { sağlanmış, sebzelerin renklerinde herhangi } \\
\text { bir kayıp gözlenmemiştir. }\end{array}$ & $\begin{array}{l}\text { Izumi, } \\
1999 .\end{array}$ \\
\hline Marul & MAB & $\begin{array}{l}10 \mathrm{dk} \text {. ASES (pH: 2.6, ORP: } 1140 \\
\mathrm{mV} \text {, SKK: } 30 \mathrm{ppm} \text { ), } 5 \text { ppm'lik } \\
\text { ozonlu su ve } 150 \text { ppm'lik NaOCl } \\
\text { uygulamas1 }\end{array}$ & $\begin{array}{l}\text { ASES ve } \mathrm{NaOCl} \text { çözeltileri ile } 2 \text { 'şer log'luk } \\
\text { azalma, ozonlu su uygulamasıyla ise } 1.5 \text { log } \\
\text { azalma sağlanmıştır. }\end{array}$ & $\begin{array}{l}\text { Koseki } \\
\text { ve ark., } \\
2001 .\end{array}$ \\
\hline Marul & $\begin{array}{l}\text { MAB ve koliform } \\
\text { bakteri }\end{array}$ & $\begin{array}{l}10 \mathrm{dk} \text {. ASES (pH:2.5, ORP: } 1140 \\
\text { mV, SKK: } 40 \text { ppm) uygulamas1 }\end{array}$ & $\begin{array}{l}\text { MAB ve koliform için sırasıyla } 1.7 \text { ve } 1.6 \\
\text { log azalma saptanmıştır. }\end{array}$ & $\begin{array}{l}\text { Koseki } \\
\text { ve Itoh, } \\
\text { 2001a. }\end{array}$ \\
\hline $\begin{array}{l}\text { Lahana, } \\
\text { marul, } \\
\text { salatalık } \\
\text { ve havuç }\end{array}$ & $\begin{array}{l}\text { Kalite özellikleri } \\
\text { (renk, klorofil, beta- } \\
\text { karoten ve askorbik } \\
\text { asit içeriği) }\end{array}$ & $\begin{array}{l}10 \mathrm{dk} \text {. ASES, } \mathrm{NaOCl}(150 \mathrm{ppm}) \\
\text { çözeltisi ve musluk suyu ile } \\
\text { muamele }\end{array}$ & $\begin{array}{l}\text { ASES, NaOCl ve musluk suyunun aynı } \\
\text { derecede kalite kaybına yol açtığ } 1 \\
\text { saptanmıstır. Lahana ve marulda klorofil } \\
\text { miktarındaki azalma \%10-20; havuçta beta- } \\
\text { karoten miktarında azalma \%30; lahana, } \\
\text { marul, salatalıkta askorbik asit miktarındaki } \\
\text { azalma ise sirasılya \%20, \%15 ve \%35 } \\
\text { olarak belirlenmiştir. }\end{array}$ & $\begin{array}{l}\text { Koseki } \\
\text { ve Itoh, } \\
\text { 2001b. }\end{array}$ \\
\hline Marul & $\begin{array}{l}\text { E. coli } \mathrm{O} 157: \mathrm{H} 7 . \text { L. } \\
\text { monocytogenes, } \\
\text { Staphylococcus } \\
\text { aureus ve } \\
\text { Salmonella } \\
\text { typhimurium }\end{array}$ & $\begin{array}{l}35^{\circ} \mathrm{C}^{\prime} \mathrm{de} 1 \mathrm{dk} \text { zaylf asidik elektolize } \\
\text { su (ZASES) (pH } 6.30 \text {, ORP } 500 \\
\mathrm{mV} \text {, SKK } 5 \mathrm{ppm} \text { ) ve ASES (pH } \\
2.6 \text {, ORP } 110 \mathrm{mV} \text {, SKK } 50 \mathrm{ppm}) \\
\text { uygulamas } 1\end{array}$ & $\begin{array}{l}\text { Bakteri sayılarında uygulama türüne göre } \\
2.5-4 \log \mathrm{kob} / \mathrm{g} \text { arası azalma saptanmıştır. }\end{array}$ & $\begin{array}{l}\text { Rahman } \\
\text { ve ark., } \\
2010 .\end{array}$ \\
\hline $\begin{array}{l}\text { Yuja } \\
\text { meyvesi }\end{array}$ & $\begin{array}{l}\text { Pestisit (bakterisid } \\
\text { ve fungisid) }\end{array}$ & $\begin{array}{l}\text { GASES (pH:2.75, ORP: } 1057 \mathrm{mV} \text {, } \\
\text { SKK: } 88.63 \text { ppm) ile mekanik } \\
\text { y1kama }\end{array}$ & $\begin{array}{l}\text { Pestisit kalıntısında \% } \% 0-\% 98.1 \text { oranında } \\
\text { azalma tespit edilmiştir. }\end{array}$ & $\begin{array}{l}\text { Sung ve } \\
\text { ark., } \\
2011 .\end{array}$ \\
\hline Marul & $\begin{array}{l}\text { S. typhimurium, } E \text {. } \\
\text { coli } \mathrm{O} 157: \mathrm{H} 7 \text { ve } L \text {. } \\
\text { monocytogenes }\end{array}$ & $\begin{array}{l}5 \mathrm{dk} .30^{\circ} \mathrm{C} \text { 'de ASES (pH 4-9, } \\
\text { SKK: } 300 \text { ppm) ile muamale }\end{array}$ & $\begin{array}{l}\text { En iyi görünüm pH'1 } 7 \text { ile olan ASES ile } \\
\text { sağlanmışıtır. Her bakteri sayısında 2'şer log } \\
\text { azalma saptanmıştır. }\end{array}$ & $\begin{array}{l}\text { Yang ve } \\
\text { ark., } \\
2003 .\end{array}$ \\
\hline
\end{tabular}

Kırmızı et, kanatlı eti, balık ve yumurta gibi çeşitli hayvansal ürünlerde gıda güvenliğinin sağlanması için elektrolize su ile birçok uygulama yapılmaktadır. Tablo 2'de bu uygulamalarla ilgili çeşitli örneklere yer verilmiştir. 
Tablo 2. Hayvansal Gıdalarda Elektrolize Su ile Yapılan Bazı Çalışmalar

\begin{tabular}{|c|c|c|c|c|}
\hline Ürün & $\begin{array}{l}\text { İncelenen } \\
\text { parametre }\end{array}$ & Uygulama & Sonuç & Kaynak \\
\hline $\begin{array}{l}\text { Çiğ tavuk } \\
\text { eti }\end{array}$ & $\begin{array}{l}\text { Koliform bakteri ve } \\
\text { MAB }\end{array}$ & $\begin{array}{l}10 \text { dk. ASES (pH:2.7, ORP: } \\
1099 \text { mV; SKK: } 20 \text { ppm), } \\
\text { ASES (pH:2.7, ORP: } 1100 \\
\text { mV, SKK: } 30 \text { ppm) ile NaOCl } \\
\text { (SKK: } 200 \text { ppm) muamele }\end{array}$ & $\begin{array}{l}\text { Koliform bakteri ve MAB sayılarındaki } \\
\text { azalma sırasıyla aşağıdaki gibidir: } \\
30 \text { ppm'lik ASES: } 1.53 \text { ve } 1.45 \log \\
20 \text { ppm'lik NaOCl: } 1.30 \text { ve } 1.32 \log \text { ve } \\
20 \text { ppm'lik ASES: } 1.24 \text { ve } 1.29 \log \end{array}$ & Aksoy, 2003 \\
\hline $\begin{array}{l}\text { Sığır, } \\
\text { keçi ve } \\
\text { domuz eti }\end{array}$ & E. coli $\mathrm{K} 12$ & $\begin{array}{l}\text { 2-12 dk., ASES (pH: } 3.03, \\
\text { ORP 759,9 mV, SKK: } 34.3 \\
\text { ppm), ALES (pH: } 10.73, \text { ORP } \\
\text {-372.4 mV, SKK: } 0.06 \mathrm{ppm} \text { ) } \\
\text { ile muamele }\end{array}$ & $\begin{array}{l}\text { Sığır, keçi ve domuz etinde en iyi azalma } \\
\text { miktarları sırasıyla şoyledir: } \\
\text { ASES: } 1.16 \log (4 \mathrm{dk} .), 1.22 \log (12 \mathrm{dk} \text {.) ve } \\
1.30 \log (10 \mathrm{dk} .) \text {; } \\
12 \mathrm{dk} \text {. boyunca ALES: } 1.61 \log , 0.96 \log \text { ve } \\
1.52 \log \end{array}$ & $\begin{array}{l}\text { Arya ve ark, } \\
2018 .\end{array}$ \\
\hline $\begin{array}{l}\text { Çiğ tavuk } \\
\text { eti }\end{array}$ & S. typhimurium & $\begin{array}{l}\text { ASES ile (pH: } 5, \text { ORP: } 925 \\
\text { mV, SKK: } 30 \text { ppm; } \\
\text { pH: } 2.6 \text { ORP: } 1076 \mathrm{mV} \text { SKK: } \\
60 \text { ppm; } \\
\text { pH: } 2.2 \text { ORP: } 1100 \mathrm{mV} \text { SKK: } \\
70 \text { ppm), } \\
15,30 \text { ve } 60 \text { sn'lik uygulama }\end{array}$ & $\begin{array}{l}\text { 0. günde } 2 \text { log'luk düşüsse rağmen } 3 \text {. ve } 7 \text {. } \\
\text { günlerde ASES'yun etkisini kaybettiği, farklı } \\
\text { ASES'lar ve uygulama sürelerinin etkileri } \\
\text { arasında fark olmadığı belirlenmiştir. }\end{array}$ & $\begin{array}{l}\text { Çil ve ark., } \\
2012 .\end{array}$ \\
\hline $\begin{array}{l}\text { Çiğ } \\
\text { domuz eti }\end{array}$ & Campylobacter coli & $\begin{array}{l}15 \text { sn. ASES ( pH 2.6, ORP: } \\
1150 \mathrm{mV}, \text { SKK:50 ppm) sprey } \\
\text { uygulamas1 }\end{array}$ & $\begin{array}{l}4^{\circ} \mathrm{C}^{\prime} \text { de } 7 \text { gün vakum ambalajda depolama } \\
\text { sonucu } 2.6 \text { log azalma saptanmıştır. }\end{array}$ & $\begin{array}{l}\text { Fabrizio ve } \\
\text { Cutter, } 2004 .\end{array}$ \\
\hline Yumurta & $\begin{array}{l}\text { L. monocytogenes, } \\
\text { mineral içeriği ve } \\
\text { renk değişimi }\end{array}$ & $\begin{array}{l}2 \% \text { sitrik asit, } \% 0.9 \mathrm{NaCl} \\
\text { çözeltisi, } 46 \mathrm{ppm} \mathrm{NES} \mathrm{ile} \\
\text { muamele }\end{array}$ & $\begin{array}{l}\text { Mineral içeriği ve renk değişimine neden } \\
\text { olmadan en iyi sonuç (2.18- } 1.74 \text { log azalma) } \\
\text { NES uygulamasından alınmıştır. }\end{array}$ & $\begin{array}{l}\text { Garcia ve } \\
\text { ark., } 2019 .\end{array}$ \\
\hline $\begin{array}{l}\text { Sazan } \\
\text { filetoları }\end{array}$ & $\begin{array}{l}\text { Besin öğeleri, } \\
\text { aminoasit } \\
\text { kompozisyonu, } \\
\text { protein } \\
\text { sindirebilirliği ve } \\
\text { yağ asidi } \\
\text { kompozisyonu }\end{array}$ & $\begin{array}{l}15 \mathrm{dk} .40 .8 \text { ppm'lik ASES } \\
\text { (pH: 2,22; ORP: } 1137 \mathrm{mV}) \\
\text { ALES (pH: } 11.6 \text { ve ORP } 885 \\
\text { mV) ve esansiyel yağ } \\
\text { bileşenleri ile muamale }\end{array}$ & $\begin{array}{l}\text { Kalite özelliklerinin etkilenmediği ve sentetik } \\
\text { koruyuculara alternatif olarak elektrolize su ve } \\
\text { esansiyel yağ bileşenlerinin kullanılabileceği } \\
\text { belirtilmiştir. }\end{array}$ & $\begin{array}{l}\text { Mahmoud } \\
\text { ve ark., } \\
2006 .\end{array}$ \\
\hline $\begin{array}{l}\text { Çiğ tavuk } \\
\text { eti }\end{array}$ & $\begin{array}{l}\text { Campylobacter } \\
\text { jejuni }\end{array}$ & $\begin{array}{l}10 \text { dk. } 50 \text { ppm'lik ASES ve } \\
\text { klorlu suya daldırma }\end{array}$ & $\begin{array}{l}\text { Her iki uygulama ile } 3 \text { log azalma } \\
\text { saptanmıştır. }\end{array}$ & $\begin{array}{l}\text { Park ve ark., } \\
2002 \mathrm{~b} .\end{array}$ \\
\hline $\begin{array}{l}\text { Sazan } \\
\text { fileto }\end{array}$ & $\begin{array}{l}\text { Raf ömrü kriterleri } \\
\text { (duyusal, kalıntı } \\
\text { klor, toplam canl, } \\
\text { MAB, } \\
\text { Enterobacteriacea) }\end{array}$ & $\begin{array}{l}5 \mathrm{dk} .100 \mathrm{ppm} \text { ASES, } 100 \\
\text { ppm ASES ve } \% 0.5^{\prime} \text { lik } \\
\text { lizozim uygulaması ve su ile } \\
\text { durulama. }\end{array}$ & $\begin{array}{l}2^{\circ} \mathrm{C}^{\prime} \text { de } 7 \text { gün vakum ambalajda depolama } \\
\text { sonucu, } 100 \text { ppm ASES ve \%0.5'lik lizozim } \\
\text { kombinasyonu en iyi sonucu vermiştir. Her iki } \\
\text { uygulama, bakteri sayılarında } 2.4-3.1 \log \\
\text { azalma sağlanmıştır. }\end{array}$ & $\begin{array}{l}\text { Palotás ve } \\
\text { ark., } 2020 .\end{array}$ \\
\hline $\begin{array}{l}\text { Pişmiş } \\
\text { karides }\end{array}$ & $\begin{array}{l}\text { Vibrio } \\
\text { parahaemolyticus }\end{array}$ & $\begin{array}{l}6 \text { gün boyunca her } 12 \text { saatte } \\
\text { yenilenerek, ASES buzu (pH } \\
\text { 2.46, ORP } 1124 \mathrm{mV}, \text { SKK: } 26 \\
\text { ppm) ile muamele }\end{array}$ & 5.1 log'a kadar azalma saptanmıştır. & $\begin{array}{l}\text { Wang ve } \\
\text { ark.,2014. }\end{array}$ \\
\hline
\end{tabular}

Sebze, meyve ve hayvansal ürünler dışındaki diğer bazı gıdalarda da elektrolize su uygulamaları mevcuttur. Tablo 3 'te bu uygulamaların birkaçından bahsedilmiştir. 
Tablo 3. Diğer Bazı Gıdalarda Elektrolize Su ile Yapılan Bazı Çalışmalar

\begin{tabular}{|c|c|c|c|c|}
\hline Ürün & $\begin{array}{l}\text { İncelenen } \\
\text { parametre }\end{array}$ & UYGULAMA & SONUÇ & KAYNAK \\
\hline Yer fistığ1 & Aflatoksin B1 & $\begin{array}{l}10-30 \text { dk., NES (pH 5.6; SKK 10- } \\
100 \text { ppm) ve ASES (pH 2.5) ve } \\
\text { ALES (pH:11.6) }\end{array}$ & $\begin{array}{l}60 \text { ppm'lik } 15 \mathrm{dk} \text {. ASES ve } 80 \text { ppm'lik } 10 \mathrm{dk} \text {. } \\
\text { NES uygulaması aflatoksin B1 miktarında } \\
\text { \%10'a kadar azalma sağlanmıştır. }\end{array}$ & $\begin{array}{l}\text { Xiong ve } \\
\text { ark., } 2012 .\end{array}$ \\
\hline \multirow{4}{*}{ Buğday } & $\begin{array}{l}\text { Deoxynivalenol } \\
\text { (DON) }\end{array}$ & \multirow{4}{*}{$\begin{array}{l}60 \text { ppm'lik ASES (pH } 2.5,3.5 \\
4.5,5.5 \text { ve } 6.5 \text { ) ve } 60 \text { ppm'lik } \\
\text { ALES (pH 8.5, 9.5, } 10.5,11.5 \text { ve } \\
\text { 12.5) ile } 45 \text { dk. muamele }\end{array}$} & $\begin{array}{l}\text { En yüksek DON eliminasyonu ASES (pH 5.5) } \\
\text { için \%57.48, ALES (pH 9.5) için \%61.60 ve } \\
\text { kontrol için \%10.63 saptanmıştır. }\end{array}$ & \multirow{4}{*}{$\begin{array}{l}\text { Lyu ve ark., } \\
2018 .\end{array}$} \\
\hline & Toplam küf & & $\begin{array}{l}\text { ASES ile önemli derecede azalma sağlanmış, } \\
\text { ALES (pH: } 8.5 \text { ve } 12.5 \text { ) ile neredeyse küf } \\
\text { tespit edilememiştir. }\end{array}$ & \\
\hline & $\begin{array}{l}\text { Kalite } \\
\text { özellikleri }\end{array}$ & & 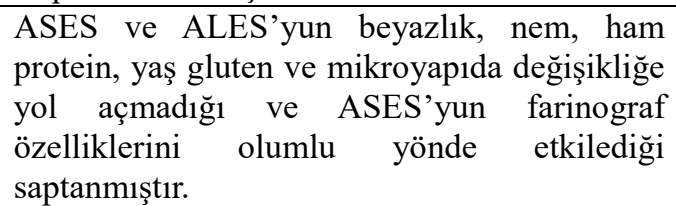 & \\
\hline & $\begin{array}{l}\text { Fusarium } \\
\text { graminearum }\end{array}$ & & $\begin{array}{l}\text { pH'1 } 5.5 \text { olan ASES ve pH'1 } 9.5 \text { olan ALES ile } \\
\text { önemli derecede azalma saptanmıştır. }\end{array}$ & \\
\hline
\end{tabular}

Gıda ile temas eden yüzey ve ekipmanların temizliği, gıda güvenliğinin sağlanması için oldukça önemlidir. CIP (Clean In Place) sistemleri de dahil olmak üzere, elektrolize su çeşitli ekipman ve yüzeylerin sanitasyonu için uygulanmaktadır (Wang ve ark., 2016). Bu uygulamalara örnekler Tablo 4'te sunulmuştur.

Tablo 4. Gıda ile Temas Eden Ekipman ve Yüzeylerde Elektrolize Su ile Yapılan Bazı Çalışmalar

\begin{tabular}{|c|c|c|c|c|}
\hline Ürün & $\begin{array}{l}\text { İncelenen } \\
\text { parametre }\end{array}$ & UYGULAMA & SONUÇ & KAYNAK \\
\hline $\begin{array}{l}\text { Bardak, } \\
\text { tabak ve } \\
\text { gümüş } \\
\text { ekipmanlar }\end{array}$ & $\begin{array}{l}\text { E.coli } \mathrm{K}-12 \text { ve } \\
\text { S. epidermis }\end{array}$ & $\begin{array}{l}\text { Kuaterner amonyum }(200 \\
\text { ppm }) \text { NaOCl }(100 \mathrm{ppm}) \\
\text { peroksiasetik asit }(1000 \mathrm{ppm}), \\
\text { sitrik asit-dodesil benzen } \\
\text { sülfonat }(10000 \mathrm{ppm}) \text { ve NES } \\
(100 \mathrm{ppm}, \mathrm{pH}: 7.4) \text { ile elde ve } \\
\text { makinede yıkama }\end{array}$ & $\begin{array}{l}\text { Her koşulda, tüm dezenfektanlarla bakteri } \\
\text { yükünde en az } 5 \text { log azalma, } \\
\text { ASES ile makine ile y1kamada } 6.9 \text { log, elde } \\
\text { yıkamada ise } 5.4 \text { log azalma saptanmıştır. }\end{array}$ & $\begin{array}{l}\text { Haondojo } \\
\text { ve ark., } \\
2009 \text {. }\end{array}$ \\
\hline $\begin{array}{l}\text { Kesme } \\
\text { tahtasi }\end{array}$ & $\begin{array}{l}\text { E. coli } \mathrm{K} 12 \text { ve } \\
\text { L. innocua }\end{array}$ & $\begin{array}{l}\text { Kesme tahtalar elde ya da } \\
\text { makinede y1kandiktan sonra } \\
23^{\circ} \mathrm{C}^{\prime} \text { de } 10 \text { sn. boyunca } \\
\text { NaOCl (SKK: } 100 \text { ppm) ve } \\
\text { NES (SKK:120 ppm, ORP: } \\
799.6 \mathrm{mV} \text {, pH: } 7.05 \text { ) ile sprey } \\
\text { uygulamas1 }\end{array}$ & $\begin{array}{l}\text { Elle y1kamada E. coli sayısı NEW için } 3.4 \log \\
\text { ve NaOCl için } 3.6 \text { log azalma, } \\
L . \text { innocua sayıs NEW için } 4.1 \log \text { ve NaOCl } \\
\text { için } 3.9 \text { log azalma, } \\
\text { Otomatik y1kamada E. coli sayısı NEW için } 4 \\
\text { log ve } \mathrm{NaOCl} \text { için } 4 \text { log azalma, } \\
\text { L. innocua sayısı NEW için } 4.2 \log \text { ve NaOCl } \\
\text { için } 3.6 \text { log azalma sağlanmıştır. }\end{array}$ & $\begin{array}{l}\text { Monnin ve } \\
\text { ark., } 2012 .\end{array}$ \\
\hline $\begin{array}{l}\text { Cam, } \\
\text { paslanmaz } \\
\text { çelik, } \\
\text { seramik } \\
\text { fayans vb. }\end{array}$ & $\begin{array}{l}\text { E. aerogenes ve } \\
\text { S.aureus }\end{array}$ & $\begin{array}{l}\text { ASES (SKK: } 10 \mathrm{ppm} \text { ) ile } \\
\text { çalkalayarak ve } \\
\text { çalkalamayarak yapılan } \\
\text { uygulama }\end{array}$ & $\begin{array}{l}\text { Çalkalamadan yapılan uygulama sonucu } \\
\text { bakteri sayılarında sırasılyla } 2.2-2.4 \log \text { ve } 1.7- \\
1.9 \text { log azalma; } \\
\text { çalkalayarak yapılan uygulamada ise yüzeyde } \\
\text { canlı hücreler } 1 \mathrm{kob} / \mathrm{cm}^{2} \text { den az tespit } \\
\text { edilmiştir. }\end{array}$ & $\begin{array}{l}\text { Park ve } \\
\text { ark, 2002a. }\end{array}$ \\
\hline $\begin{array}{l}\text { Teflon, } \\
\text { paslanmaz } \\
\text { çelik ve } \\
\text { seramik } \\
\text { yüzeyler }\end{array}$ & $\begin{array}{l}\text { MAB, } S \text {. } \\
\text { typhimurium, } L \text {. } \\
\text { monocytogenes, } \\
\text { verotoxigenic } E \text {. } \\
\text { coli } \mathrm{O} 157: \mathrm{H} 7 \text { ve } \\
\text { S. aureus }\end{array}$ & $\begin{array}{l}30 \mathrm{sn} .110 \text { ppm'lik ASES (pH } \\
2.69 \text {, ORP } 1135 \mathrm{mV} \text { ) ile } \\
\text { muamele }\end{array}$ & $\begin{array}{l}\text { Tüm bakteri populasyonunda } 8 \log \text { azalma } \\
\text { saptanmıştır. }\end{array}$ & $\begin{array}{l}\text { Serraino ve } \\
\text { ark., } 2010 .\end{array}$ \\
\hline $\begin{array}{l}\text { CIP } \\
\text { ekipmanlar1 }\end{array}$ & $\begin{array}{ll}\text { Kalınt } & \text { ATP ve } \\
\text { protein } & \end{array}$ & $\begin{array}{l}54.6^{\circ} \mathrm{C} \text { 'de } 20,5 \mathrm{dk} \text {. ALES (pH } \\
11.65-11.66 \text {, ORP (-869)-(- } \\
879) \mathrm{mV}) \text { ile yıkama, ardından }\end{array}$ & Kalıntı ATP ve protein tespit edilememiştir. & Yu, 2014. \\
\hline
\end{tabular}




\begin{tabular}{|c|c|c|c|c|}
\hline & & $\begin{array}{l}25^{\circ} \mathrm{C}^{\prime} \mathrm{de} \quad 10 \mathrm{dk} . \text { ASES }(\mathrm{pH} \\
2.38-2.40, \text { ORP } 1166-1169 \\
\mathrm{mV} \text {, SKK: } 82.6-84.6 \mathrm{ppm}) \text { ile } \\
\text { sanitasyon }\end{array}$ & & \\
\hline $\begin{array}{l}\text { Kümes } \\
\text { hayvanları } \\
\text { için plastik } \\
\text { taşıma } \\
\text { kafesleri }\end{array}$ & S. enteritidis & $\begin{array}{l}20-80 \text { sn. ZASES (pH: 6.15- } \\
6.56 \text {, SKK: 0-90 ppm, ORP: } \\
\text { 398.7-835.4 mV), ZASEW } \\
\text { (pH: 6.49-6.56, SKK: 10-90 } \\
\text { ppm, ORP: 798.5-835.4 mV) } \\
\text { spreylenmesi + UV uygulama }\end{array}$ & $\begin{array}{lrrrr}\text { En az } 70 & \text { sn'lik } & \text { ZASES } & (90 & \text { ppm })+ \text { UV } \\
\text { uygulaması ile } & \% 100 & \text { S. } & \text { enteritidis } \\
\text { inaktivasyonu sağlanmıştır. } & & \end{array}$ & $\begin{array}{l}\text { Zang ve } \\
\text { ark., } 2019\end{array}$ \\
\hline
\end{tabular}

Çeşitli mikroorganizma süspansiyonları üzerine de elektrolize su ile yapılan çalışmalar mevcuttur. Tablo 5'te bu çalışmalara bazı örnekler verilmiştir.

Tablo 5. Mikroorganizma Süspansiyonları Üzerinde Elektrolize Su ile Yapılan Bazı Çalışmalar

\begin{tabular}{|c|c|c|c|}
\hline Ürün & İncelenen parametre & UYGULAMA & SONUÇ \\
\hline $\begin{array}{l}\text { E. coli. } S . \\
\text { typhimirum, } S \text {. } \\
\text { aureus, } \\
\text { S.cerevisiae, B. } \\
\text { cereus }\end{array}$ & $\begin{array}{l}60 \mathrm{dk} \text {. ASES (pH 2.5; ORP }>1150 \mathrm{mV}) \text { ile } \\
\text { muamele }\end{array}$ & $\begin{array}{l}\text { 10-40 dk.'llk uygulama ile } B \text {. cereus harici } \\
\text { tüm bakteriler inhibe edilmiştir. }\end{array}$ & $\begin{array}{l}\text { Jung ve ark., } \\
1996 .\end{array}$ \\
\hline E.coli & $\begin{array}{l}\text { UV ile scan edilen ZAES (pH: 5.58-6.23, } \\
\text { SKK: 0.35-14.3 ppm, ORP 869-1048 mV) ve } \\
\text { ASES uygulamaları (pH 2.5-3.74, SKK: } 1.3- \\
24.5 \text { ppm, ORP } 1019-1134 \mathrm{mV})\end{array}$ & $\begin{array}{l}\text { ASES ile inaktivasyon sağlanmış ve klor } \\
\text { bazlı dezenfektanlara alternatif olarak } \\
\text { önerilmiştir. }\end{array}$ & $\begin{array}{l}\text { Hao ve ark., } \\
2012 .\end{array}$ \\
\hline $\begin{array}{l}\text { E. coli } \\
\text { O157:H7. L. } \\
\text { monocytogenes, } \\
\text { S. aureus ve } S . \\
\text { typhimurium }\end{array}$ & $\begin{array}{l}\text { ZASES (pH 6.30, ORP } 500 \mathrm{mV}, \text { SKK: } 5 \text { ppm) } \\
\text { ve ASES (pH 2.6, ORP } 110 \mathrm{mV}, \text { SKK: } 50 \\
\text { ppm) uygulaması } \\
(\text { Süre } 1,3,5,7 \text { ve } 10 \mathrm{dk} \text {. ve sicaklık } 4,15,23 \text {, } \\
\left.35 \text { ve } 50^{\circ} \mathrm{C}\right)\end{array}$ & $\begin{array}{l}\text { Bakteri sayılarında uygulama türüne göre } \\
1.7-6.6 \text { log azalma saptanmıştır. }\end{array}$ & $\begin{array}{l}\text { Rahman ve } \\
\text { ark., } 2010 .\end{array}$ \\
\hline $\begin{array}{l}\text { E. aerogenes, } S . \\
\text { aureus }\end{array}$ & $\begin{array}{l}\text { ASES (pH: 2.53-3.18; ORP: } 1116-1178 \mathrm{mV} \text {; } \\
\text { SKK: 11.3-53.1 ppm) ile muamele }\end{array}$ & $\begin{array}{l}\text { Bakteri sayılarında } \geq 9 \text { log azalma } \\
\text { saptanmıştır. }\end{array}$ & $\begin{array}{l}\text { Park ve ark, } \\
\text { 2002a. }\end{array}$ \\
\hline B. cereus & $\begin{array}{l}30 \mathrm{dk} \text {. Ultrason ve } 30 \text { ppm'lik AEW } \\
\text { uygulamas }\end{array}$ & $\begin{array}{l}\text { Bakteri spor sayılarında } 2.29 \log \text { azalma } \\
\text { sağlanmıştır. }\end{array}$ & $\begin{array}{l}\text { Lv ve ark., } \\
2020 .\end{array}$ \\
\hline
\end{tabular}

\section{Sonuç}

Gerek toplu tüketim yerlerinde gerekse ambalajlanarak piyasaya sunulan kullanıma ya da tüketime hazır sebze-meyve gibi ürünlere etkin bir dezenfeksiyon işlemi uygulanması gıda güvenliği açısından oldukça önemlidir. Bunun yanı sıra et, balık, yumurta vb. gibi hayvansal gıdaların üretimi esnasında ve satışı öncesinde uygun dezenfektan çözeltilerle dekontamine edilmesi, ayrıca her türlü gıda üretim alanlarının ve gıdayla temas eden ekipman ya da yüzeylerin dekontaminasyonu da gıda güvenliğinin sağlanmasında önemli basamaklardır. $\mathrm{Bu}$ dezenfeksiyon uygulamaları ile gıdaların başlangıç mikroorganizma yükü önemli ölçüde azaltılabilmektedir. Elektrolize su günümüzde bu amaçla yaygın olarak kullanılmaya başlanan ve başarılı sonuçlar alınan modern dezenfektanlardan biridir. Ancak bakteri sporları ve makro parazitler üzerinde etkinliği sınırlı olarak değerlendirilmektedir. Dolayısıyla her türlü gıda üretim ya da satış tesislerinde \%100 güvenli gıdaya ulaşmayı amaçlayan entegre bir gıda güvenliği sisteminin (ISO 22000 vb.) gerektirdiği önlemler alınmalı; İyi Hijyen Uygulamaları (GHP) ve İyi Üretim Uygulamaları (GMP) gerekliliklerine uyulmalıdır.

\section{Kaynakça}

Aksoy, A., (2003). Bazı taze sebzeler ve çiğ tavuk etinde yüzey dekontaminasyonu uygulamalarının incelenmesi. Yüksek Lisans Tezi. İstanbul Teknik Üniversitesi, Fen Bilimleri Enstitüsü, İstanbul, Türkiye.

Al-Haq MI, Seo Y, Oshita S. Kawagoe Y., (2002). Disinfection effects of electrolyzed oxidizing water on suppressing fruit rot of pear caused by Botryosphaeria berengeriana. Food Res Inter, 35, 657-664.

Anonim, (2018a). http://www.efsa.europa.eu/en/press/news/180726. Erişim tarihi: 21.04.2020

Anonim, (2018b). https://efsa.onlinelibrary.wiley.com/doi/10.2903/sp.efsa.2018.EN-1448. Erişim tarihi: 22.04.2020 
Anonim, (2018c). http://www.drinktech.net/makaleler/elektrolize-su-ve-cesitlerinin-gidalarda-ve-gida-sektorunde-kullanimi 55.html. Erişim tarihi: 22.04 .2020

Anonim, (2011). Güvenli ve kaliteli su ürünleri üretiminde uygulanan son teknolojiler 1. http://www.dunyagida.com.tr/haber.php?nid=2031. Erișim tarihi: 26.03 .2015

Anonim, (2012). Gıdalarda ve su ürünlerinde atımlı 1şı ve elektrolize okside su uygulamaları. http://www.gidateknolojisi.com.tr/haber/2012/10/gidalarda-ve-su-urunlerinde-atimli-isik-ve-elektrolize-okside-su-uygulamalari. Erişim tarihi: 22.04 .2020

Appleton, H. (2000). Control of Food-borne Viruses, British Medical Bulletein, 56 (1), 172-183.

Arya, R., Bryant, M., Degala, H.L., Mahapatra, A.K., (2018). Effectiveness of a low-cost household electrolyzed water generator in reducing the populations of Escherichia coli K12 on inoculated beef, chevon, and pork surfaces, Journal of Food Process ing and Preservation, 2018; e13636.

Athayde, D.R., Flores, D.R.M., Silva, J.S., Silva, M.S., Genro, A.L.G., Wagner, R., Campagnol, P.C.B., Menezes, C.R., Cichoski, A.J., (2018). Characteristics and use of electrolyzed water in food industries, International Food Research Journal, 25(1): 11-16.

Buck, J.W., Iersel, M.W., Oetting, R.D. and Hung, Y.C., (2003). Evaluation of acidic electrolyzed water for phytotoxic symptoms on foliace and flowers of bedding plants, Crop Protection, 22, 73-77.

Choi, S.Y., Cho, M.A., Hong, Y.P., (2008). Effects of washing treatments with different components on removal of pesticide residues and microorganisms in 'fuji' apples, Korean Journal of Horticultural Science Technology, 26(3), 251-257.

Fabrizio, K.A., Cutter, C.N., (2004). Comparison of electrolyzed oxidizing water with other antimicrobial interventions to reduce the pathogens on fresh pork. Meat Sci. 68, 463-468.

Graca, A., Nunes, C., Salazar, M. (Editör: Erkan, M; Aksoy, U.), (2010). Efficacy of neutral and acidic electrolyzed water for reducing microbial contamination on fresh-cut fruits. VI International Postharvest Symposium, Acta Horticulturae, 877, 649-655.

Günaydın, M., Esen, Ş., Yanık, K., Ünal, N., Karadağ, A., Odabaşı, H., Birinci, A., (2012). Süper Okside Suyun Çeşitli Mikroorganizmalara Karşı In-vitro Etkinliğinin Araştırılması, 1. Sterilizasyon Ameliyathane Dezenfeksiyon (SAD) Sempozyumu The Anatolian Hotel, Gaziantep, 3-6 Ekim 2012.

Hao, J., Wuyundalai, Liu H., Chen, T., Zhou, Y., Su, Y.C., Li, L., (2011). Reduction of pesticide residues on fresh vegetables with electrolyzed water treatment, Journal of Food Science, 76(4), 520-524.

Hao, J., Qiu, S., Li, HY., Chen, TP., Liu, HJ., Li, LT., (2012). Roles of hydroxyl radicals in electrolyzed oxidizing water (EOW) for the inactivation of Escherichia coli. International Journal of Food Microbiology, 155(3): 99-104.

Haondojo, A., Lee, J., Hipp, J., Pascall, MA., (2009). Efficacy of electrolyzed water and an Acidic Formulation Compared with Regularly Used Chemical Dezenfektans for Tableware Sanitization during Mechanical and Manual Ware-Washing Protocols. Journal of Food Protection, 72(6):1315-1320.

Hati, S., Mandal, S., Minz, P.S., Vij, S., Khetra, Y., Singh, B.P., Yadav, D., (2012). Electrolyzed oxidized water (EOW): non-thermal approach for decontamination of food borne microorganisms in food industry. Food and Nutrition Sciences, 3, 760-768.

Hayta, E., (2014). Elektrolize suyun kiraz kalitesine etkisi. Yüksek Lisans Tezi. Çanakkale Onsekiz Mart Üniversitesi, Fen Bilimleri Enstitüsü, Çanakkale, Türkiye.

Hricova, D., Stephan, R., Zweifel, C., (2008). Electrolyzed water and its application in the food industry. Journal of Food Protection, 71(9):1934-1937.

Hsu SY. (2005). Effects of flow rate, temperature and salt concentration on chemical and physical properties of electrolyzed oxidizing water. J of Food Engineer, 66, 171-176.

Huang YR, Hung YC, Hsu SY, Huang YW, Hwang DF., (2008). Application of electrolyzed water in the food industry. Food Control 19, 329-345.

Izumi, H., (1999). Electrolyzed water as a disinfectant for fresh-cut vegetables, Journal of Food Science, 64, 2, 536-539.

İplikçioğlu Çil, G., Demirel, Y. N., Şireli, U.T., (2012). Inactivation of Salmonella typhimurium on poultry meat by electrolyzed water, Vet Hekim Der Derg 83(2): 48-53.

Jung, S.W., Park, K.J., Park, B.I. and Kim, Y.H., (1996). Surface sterilization effect of electrolyzed acid-water on vegetable, Korean Journal of Food Science and Technology, 28, 6, 1045-1051.

Kim, C., Hung, Y.C., Brackett, R.E. and Frank, J.F., (2001). Inactivation of Listeria monocytogenes biofilms by electrolyzed oxidizing water, Journal of Food Processing Preservation , 25, 91-100.

Kiura, H., Sano, K., Morimatsu, S., Nakano, T., Morita, C., Yamaguchi, M., Maeda, T. and Katsuoka, Y., (2002). Bacteriocidal activity of electrolyzed acid water from solution containing sodium chloride at low concentration, in comparison with that at high concentration, Journal of Microbiological Methods, 49, 285-293.

Koseki, S., Yoshida, K., Isobe, S. and Itoh, K., (2001). Decontamination of lettuce using acidic electrolyzed water, Journal of Food Protection, 64, 5, 652-658.

Koseki, S., Fujiwara, K. and Itoh, K., (2002). Decontaminative effect of frozen acidic electrolyzed water on lettuce, Journal of Food Protection, 65, 2, 411-414.

Koseki S, Itoh K, (2000). Fundament properties of electrolyzed water. J of The Japanese Soc for Food Sci and Technol.-Nippon Shokuhin Kagaku Kogaku Kaishi, 47, 5: 390-393.

Koseki, S., Itoh, K., (2001a). Prediction of microbial growth in fresh-cut vegetables treated with acidic electrolyzed water during storage under various temperature conditions, Journal of Food Protection, 64, 12, 1935-1942.

Koseki, S., Itoh, K., (2001b). The effect of acidic electrolyzed water on the quality of cut vegetables, Journal of the Japanese Society for Food Science and Technology, 48, 5, 365-369.

Külekçi, G., (2005) Klor verici dezenfektanların kullanım ilkeleri hangi şartlarda, hangi amaçlarla kullanılır? Türevleri nelerdir? 4. Ulusal Sterilizasyon Dezenfeksiyon Kongresi, sayfa 207-219. 
Len, S. V., Hung, Y. C., \& Chung, D. (2002). Effects of storage conditions and pH on chlorine loss on electrolyzed oxidizing (EO) water. J. of Agric. Food Chem., 50 209-212.

Lv,, R., Muhammed, A.I., Zou, M., Yu, Y., Fan, L., Zhou, J., Tian, D., Ye, X., Guo, M., Liu, D., (2020). Hurdle enhancement of acidic electrolyzed water antimicrobial efficacy on Bacillus cereus spores using ultrasonication, Applied Microbiology and Biotechnology, https://doi.org/10.1007/s00253-020-10393-6.

Lyu, F., Gao, F., Zhou, X., Zhang, J., Ding, Y., (2018). Using acid and alkaline electrolyzed water to reduce deoxynivalenol and mycological contaminations in wheat grains, Food Control, 88, 98-104.

Mahmoud BSM, Yamazaki K, Miyashita K, Shin II, Suzuki T., (2006). A new technology for fish preservation by combined treatment with electrolyzed $\mathrm{NaCl}$ solutions and essential oil compounds. Food Chem. 99, 656-662.

Millioğlu, Ö., (2006). Elektrolize suyun Vicia faba L. üzerine genotoksik etkisinin kontrolü. Yüksek Lisans Tezi. Gebze Yüksek Teknoloji Enstitüsü, Mühendislik ve Fen Bilimleri Enstitüsü, Gebze, Türkiye.

Monnin A., Lee J., Pascall M. A., (2012). Efficacy of neutral electrolyzed water for sanitization of cutting boards used in the preparation of foods, Journal of Food Engineering, 110, 541-546.

Onishi, R., Hara, Y., Arai, E., (2001). Improvement of eating quality and preservability of cooked rice obtained from aged rice grains by weak electrolyzed cathode water. J of The Japanese Soc for Food Sci and Technol-Nippon Shokuhin Kagaku Kogaku Kaishi, 48 (2): 112-118.

Özer, C.O., Kılı̨̧, B., (2012). Et endüstrisinde elektrolize yükseltgen su uygulaması, 11. Türkiye Gıda Kongresi, 10-12 Ekim, Hatay.

Palotás, P., Palotás Jr., P., Jonas, G.,, Lehel, J., Friedrich, L., (2020). Preservative Effect of Novel Combined Treatment with Electrolyzed Active Water and Lysozyme Enzyme to Increase the Storage Life of Vacuum-Packaged Carp, Hindawi Journal of Food Quality, Article ID 4861471, https://doi.org/10.1155/2020/4861471.

Park, H., Hung, Y. C. and Kim, C., (2002a). Effectiveness of electrolyzed water as a dezenfektan for treating different surfaces, Journal of Protection, 65, 8, 1276-1280.

Park H, Hung YC, Brackett RE., (2002b). Antimicrobial effect of electrolyzed water for inactivating Campylobacter jejuni during poultry washing. Int J of Food Microbiol, 72 (1-2): 77-83.

Poçan, H.B., Karakaya, M., Ulusoy, K., (2011). Elektrolize suyun gıda endüstrisinde kullanımı. Gıda, 36 (3):169-176.

Poçan, H.B., 2012. Elektrolize suyun sığır ve tavuk etlerinin bazı emülsiyon karakteristikleri üzerine etkisi. Yüksek Lisans Tezi. Selçuk Üniversitesi, Fen Bilimleri Enstitüsü, Konya, Türkiye.

Rahman, S. M. E., Ding, T., Oh, D.H., (2010). Effectiveness of low concentration electrolyzed water to inactivate foodborne pathogens under different environmental conditions. International Journal of Food Microbiology, 139(3): 147-153.

Rahman, S. M. E., Khan, I., Oh, D.H., (2016). Electrolyzed water as a novel sanitizer in the food industry: current trends and future perspectives. Comprehensive Reviews in Food Science and Food Safety., 15, 471-490.

Rivera-Garcia, A., Santos-Ferro, L., Ramirez-Orejel, J.C., et al., (2019). The effect of neutral electrolyzed water as a disinfectant of eggshells artificially contaminated with Listeria monocytogenes. Food Sci Nutr.,7:2252-2260.

Serraino, A., Veronese, G., Alonso, S., Matera, R., Lugoboni, B., Giacometti, F., (2010). Bactericidal activity of electrolyzed oxidizing water on food processing services. Italian Journal of Food Science, 22(8):222-228.

Sharma, R.R., Demirci, A., (2002). Treatment of Escherichia coli 0157:H7 inoculated alfalfa seeds and sprouts with electrolyzed oxidizing water, International Journal of Food Microbiology, 2676, 1-7.

Sung, J.M., Kwon, K.H., Kim, J.H., Jeong, J.W., (2011). Effect of washing treatments on pesticide residues and antioxidant compounds in Yuja (Citrus junos Sieb ex Tanaka). Food Sci. Biotechnol., 20(3): 767-773.

Turantaş, F., Ersus-Bilek, S., Sömek, Ö., Kuş̧̧u, A., (2018). Decontamination effect of electrolyzed water washing on fruits and vegetables, Journal of Microbiology, Biotechnology and Food Sciences, 7(4), 337-342.

Venkitanarayanan KS, Ezeike GOI, Hung YC, Doyle MP., (1999b). Efficacy of electrolyzed oxidizing water for inactivating Escherichia coli O157:H7, Salmonella enteritidis, and Listeria monocytogenes. Appl and Environment Microbiol, 65, 4276-4279.

Wang, J.J., Lin, T., Li, J.B., Liao, C., Pan, Y.J., Zhao, Y., (2014a). Effect of acidic electrolyzed water ice on quality of shrimp in dark condition. Food Control 35, 207-212.

Wang, X. Demirci, A., Puri, V.M., (2016). Electrolyzed Oxidizing Water for Food and Equipment Decontamination, Handbook of Hygiene Control in the Food Industry, chapter 34, 503-520.

Xiong, K., Liu, HJ., Li, LT., (2012). Product identification and safety evaluation of aflatoxin B-1 decontaminated by electrolyzed oxidizing water. Journal of Agricultural and Food Chemistry, 60(38): 9770-9778.

Yang, H., Swem B.L., Li Y., (2003). The effect of pH on inactivation of pathogenic bacteria on fresh-cut lettuce by dipping treatment with electrolyzed water. J of Food Sci, 68, 1013-1017.

Yoshida, K., Achiwa, N., ve Katayose, M., (2004). Application of electrolyzed water for food industry in Japan, Specialized Engineering Dept., Hoshizaki Electric Co., Ltd., 3-16 Minamiyakata, Sakae, Toyoake, Aichi, 470-1194.

Yu, Y., (2014). Evaluation of electrolyzed water for clean-in-place of dairy processing equipment, Yüksek Lisans Tezi. The Pennsylvania State University The Graduate School, College of Agricultural Sciences, Pensilvanya, ABD.

Yudin, R., Zuniga, M., ; Vergara, J., Edited by:Arauz, LF; Fonseca, JM; Hewett, EW., (2011). Revisiting the use of electrolyzed water as a fresh produce dezenfectant. International Conference on Postharvest and Quality Management of Horticultural Products of Interest for Tropical Regions, Acta Horticulturae, 906, 225-233.

Zang, Y..T., Bing, S., Li, Y.J., Shu, D.Q., (2019). Application of slightly acidic electrolyzed water and ultraviolet light for Salmonella enteritidis decontamination of cell suspensions and surfaces of artificially inoculated plastic poultry transport coops and other facility surfaces, Poultry Science Association Inc., 1-7. 